\title{
A implantação do Ensino Remoto Emergencial em escolas públicas e particulares da Educação Básica: estudo de caso em um município mineiro
}

\section{Karla Emanuella Veloso Pinto ${ }^{1}$}

Ronei Ximenes Martins ${ }^{2}$

\section{RESUMO}

O objetivo deste artigo é relatar estratégias adotadas nos sistemas público e privado de Educação Básica para manutenção das atividades letivas durante a pandemia da COVID-19. A pesquisa, qualitativa e exploratória, deu-se a partir de entrevistas com diretoras de 2 escolas públicas e 2 particulares de uma cidade com cerca de 100 mil habitantes no interior de Minas Gerais. A metodologia orienta-se pela Teoria Fundamentada em Dados. Foram categorizados elementos de semelhanças e diferenças de estratégias educacionais adotadas e realizado mapeamento dessas estratégias para gerar referenciais em futuras análises de consequências. Trata-se, portanto, da primeira aproximação sistêmica com o fenômeno, geradora de hipóteses que nortearão novas investigações quando a pandemia for vencida.

Palavras-chave: Covid-19. Gestão Educacional. Recursos Educacionais Digitais. Teoria Fundamentada em Dados.

\footnotetext{
${ }^{1}$ karlaveloso4@gmail.com - Universidade Federal de Lavras - UFLA

2 rxmartins@ufla.br - Universidade Federal de Lavras - UFLA
} 
The implementation of emergency remote education in public and private basic education schools: a case study in Minas Gerais/Brazil

\section{ABSTRACT}

The purpose of this article is to report on strategies adopted in the public and private systems of basic education to maintain teaching activities during the Covid-19 pandemic. The research was qualitative and exploratory and it took place through interviews with principals from 2 public and 2 private schools in a city with around 100 thousand inhabitants. The methodology is guided by Grounded Theory. Elements of similarities and differences in the educational strategies adopted were categorized and these strategies were mapped to generate references in future consequences analyzes. It is therefore the first systemic approach to the phenomenon, which generates hypotheses that will guide new investigations when the pandemic is overcome.

Keywords: COVID-19. Educational Administration. Educational Technology. Grounded Theory. 
As consequências imediatas da disseminação da COVID-19 são de domínio público. A necessidade de isolamento social como protocolo de segurança ocasionado pela pandemia levou diversos governos a decretar a suspensão das atividades letivas presenciais nas escolas de Educação Básica, Técnica e no Ensino Superior. Segundo a UNESCO (2021), mais de 1,5 bilhão de estudantes e jovens em todo o planeta estão sofrendo ou já foram afetados pelo impacto do fechamento de escolas e universidades em decorrência da pandemia.

A Organização de Estados Ibero-Americanos para a Educação, a Ciência e a Cultura (OEI) divulgou em março de 2020 um Roteiro para Orientar a Resposta Educativa à Pandemia da COVID19, elaborado por Fernando M. Reimers, diretor da Global Education Innovation Initiative na Universidade de Harvard, e Andreas Schleicher, diretor do departamento de Educação e Competências da OCDE, destacando que os líderes educacionais devem adotar uma abordagem proativa para contribuir na mitigação do impacto da pandemia, bem como prevenir a perda de aprendizagem durante o período de distanciamento social necessário.

Para Reimers e Schleicher (2020), como uma pandemia é um desafio adaptativo por excelência, foi necessário criar oportunidades de aprendizagem rápida e de melhoria contínua. Os autores destacam também que, para enfrentar esse desafio adaptativo, a colaboração é essencial, todos precisam se aperfeiçoar e sair da zona de conforto a fim de realizar o trabalho de educar.

Diante desse contexto ainda não vivenciado nas realidades educacionais contemporâneas, as escolas tiveram que buscar estratégias para implementação de atividades didáticas remotas, com ou sem uso das Tecnologias Digitais de Informação e de Comunicação (TDIC), que poderiam acontecer por meio de reuniões com grupos de estudantes por aplicativos, por meio de lives, debates, produção de vídeos, material de estudo dirigido, dentre outras ferramentas e metodologias que atenderiam às características específicas de cada ação pensada pelo professor. Tais estratégias são objeto de investigação de grupos de pesquisa em todo o mundo, constituindo-se uma fonte preciosa de dados que, sistematizadas em relatos de pesquisa, virão a se transformar em corpus que possibilitarão melhor entendimento de causas, consequências e desdobramentos das ações educacionais adotadas no período da pandemia.

Esta investigação tem o interesse de compreender as estratégias que escolas de Educação Básica, públicas e particulares, desenvolveram para que as atividades de ensino-aprendizagem pudessem continuar durante a pandemia. Analisar casos e experiências educacionais nesse momento histórico contribuirá para a consolidação do conhecimento construído sobre como os sistemas de ensino escolar agiram e que consequências suas estratégias de enfrentamento geraram. $O$ objetivo deste artigo é, portanto, relatar resultados preliminares da investigação em curso sobre as estratégias adotadas pelos sistemas público e privado de Educação Básica para manter as atividades letivas durante a pandemia da COVID-19, com foco na incorporação de tecnologias digitais de informação e comunicação e metodologias de Ensino Híbrido. 


\section{CONTEXTO EDUCACIONAL GERADO PELA COVID-19: POSSÍVEIS APROPRIAÇÕES TEÓRICAS}

Segundo Martins (2020), a pandemia da COVID-19 abriu possibilidade de a sociedade se adaptar, rapidamente, a determinados avanços oferecidos pelas tecnologias de informação e comunicação, principalmente no que se refere à forma de "fazer o ensino-aprendizagem". Isso pode ser uma tendência, mas não se traduz, necessariamente, em um rompimento radical com o status educacional pré-pandêmico.

O Ensino Remoto Emergencial (ERE) foi uma solução temporária e emergencial - como o próprio nome destaca - que permitiu às instituições de ensino a possibilidade de manter, dentro das circunstâncias possíveis, as atividades de ensino fora do espaço físico da escola, no contexto da pandemia. São estratégias didáticas e pedagógicas criadas para diminuir os impactos das medidas de isolamento social sobre a aprendizagem. Tais estratégias podem incluir a mediação por TDIC, ou não, e ajudam a manter os vínculos intelectuais e emocionais dos estudantes e da comunidade escolar durante tal período. Para Behar (2020), o termo "remoto" significa distante no espaço e se refere a um distanciamento geográfico. 0 ensino é considerado remoto, porque os professores e alunos estão impedidos, por determinação legal, de frequentarem instituições educacionais para evitar a disseminação do vírus. É emergencial, porque do dia para noite o planejamento pedagógico para o ano letivo de 2020 teve que ser engavetado e novos planos e ações educativas colocados em prática sem que se pretendesse, conscientemente e de forma planejada, introduzir o modelo híbrido de organização curricular.

É relevante destacar que nem todos os atores do processo educacional apresentam o mesmo nível de acesso e de competência para utilizar os recursos digitais como suporte à educação escolar, conforme demonstram artigos e pesquisas sobre o tema (RIBEIRO, 2021; ARRUDA, 2018; 2020; MARTINS; PAIVA, 2017).

Com o isolamento social e a necessidade implícita de uso das tecnologias digitais (TDIC) para o restabelecimento da comunicação, interação e troca de informações entre pessoas, diversas instituições educacionais buscaram meios para dar continuidade à realização das atividades pedagógicas. Conforme salienta Arruda (2020), o contexto contemporâneo apresenta opções e possibilidades bem diferentes das emergências pandêmicas do passado. Uma delas diz respeito à disseminação de tecnologias digitais de informação e comunicação - sobretudo a internet.

Para além dos requisitos técnicos e de disponibilidade de artefatos, há outro lado nessa necessidade de mediação por recursos educacionais digitais. A apropriação das TDIC teve como base modelos e plataformas que combinam atividades síncronas e assíncronas utilizadas na Educação a Distância e em cursos semipresenciais que seriam, hipoteticamente, de fácil acesso e manuseio para os professores e estudantes. Tal base se sustenta, predominantemente, no conhecimento científico, tecnológico e metodológico disponíveis sobre Educação a Distância e de Educação Mediada por Tecnologias - ou Tecnologia Educacional. Será necessário, entretanto, em um futuro próximo, questionar cientificamente a adequação desse referencial teórico para sustentar as decisões e ações desencadeadas para a continuidade das atividades letivas com distanciamento físico entre professores e estudantes, de forma emergencial e massiva, quando todas as escolas tiveram que ser, abruptamente, fechadas. 
Neste contexto de incertezas, também quanto à pertinência dos pressupostos teóricos existentes, a análise do fenômeno educacional no momento presente pode ser orientada pela Teoria Fundamentada em Dados (TFD). A TFD dá suporte metodológico adequado para a observação exploratória da realidade factual, pois permite elaborações e análises que resultam em uma fundamentação, e não o oposto (CHARMAZ, 2009). Permite, também, questionar os pressupostos existentes e articular novos aportes conceituais a partir dos aprendizados obtidos da análise crítica da realidade vivenciada pelas escolas durante a pandemia.

Tendo a TFD como pressuposto de investigação, desconsidera-se, por exemplo, o determinismo apontado por Moran (2013), quando afirma que, tendo a escola papel social fundamental como espaço de produção da cultura, as tecnologias devem ser encaradas como meios para promover o desenvolvimento das potencialidades físicas, cognitivas e afetivas dos alunos.

Segundo Moran (2007), o ambiente on-line mais colaborativo pode ajudar alunos que têm dificuldade de concentração, de gerenciamento do tempo, criando grupos para pesquisa, atividades colaborativas, bem como acompanhando professores orientadores de aprendizagem. $O$ autor destaca que a aprendizagem on-line é uma constante no dia a dia, no trabalho, em casa, na vida, e que a educação precisa incorporar as possibilidades desses novos ambientes para uma educação ativa e transformadora.

Kenski (2003) também vai ao encontro de Moran e aponta que centenas de universidades e colégios do mundo inteiro já possuem seus espaços de estudos em ambientes virtuais, não se tratando de simples projetos de Educação a Distância, mas de novas concepções de educação em que são utilizadas as mais atuais tecnologias digitais para se aprender mais e melhor. Questionou-se, dado o fenômeno de restrições vivenciado, até que ponto tais vantagens se tornaram evidentes e eficientes no contexto do ERE.

Há abundância de autores que apresentam as TDIC como um benefício educacional per si e que sua inserção no ambiente escolar é irreversível. Os resultados encontrados por Peixoto e Araújo (2012) sobre as relações entre as tecnologias e a educação apontaram dois polos discursivos bastante característicos da literatura produzida sobre a educação mediada por tecnologias no Brasil na primeira década deste século. Segundo os referidos autores, na abrangente produção analisada, foi estudada por eles mesmos a produção bibliográfica publicada entre 1997 a 2007, e que se distribui entre os trabalhos que se baseiam "nas prescrições normativas para a incorporação dos instrumentos tecnológicos (visão instrumental), [ou] aqueles que impõem as TIC como uma fatalidade no seio das escolas (determinismo tecnológico)" (PEIXOTO; ARAÚJO, 2012, p. 256).

Destaca-se, portanto, que a adoção dos artefatos tecnológicos digitais como a solução possível para o problema da paralisação provocada pela pandemia da COVID-19 é fruto de um processo histórico de apropriação das TDIC como instrumentos que pretensamente trazem "benefícios educacionais". Nessa perspectiva, sua incorporação no contexto escolar seria inegável, independentemente das condições e contextos de adoção. Tal tipo de premissa merece observação crítica, e o processo educacional desenvolvido durante o longo fechamento das escolas, que ocorre neste momento histórico, é fenômeno investigativo privilegiado para 
reflexões e questionamentos sobre os limites e possibilidades da incorporação das TDIC no sistema educacional.

Almeida e Valente (2011) apontam que essa incorporação das TDIC é multifatorial e dentre os fatores identificados destacam-se a formação do docente e a atuação dos gestores. Moran (2007) indica como necessária uma visão que não se prenda apenas ao papel do professor, defendendo que as transformações relacionadas ao uso das TDIC "[...] afetam tudo e todos: gestores, professores, alunos, empresas, sociedade, metodologias, tecnologias, espaço e tempo" (MORAN, 2007, p. 10). O professor não deixa de ser essencial ao processo formal de ensinoaprendizagem, mas não pode, sozinho, resolver as complexas questões que envolvem a posição da escola diante das tecnologias digitais disponíveis.

Reconhecer as diferentes perspectivas engendradas nas opções de gestão adotadas pelas instituições educacionais durante a pandemia auxilia no entendimento de como as escolas percebem e adotam as propostas de inovação, ou "pseudoinovação", que acompanham a inserção das TDIC nas práticas de sala de aula. Pesquisas como as de Pasinato e Vosgerau (2011), Carvalho e Martins (2017) e Silva (2019) ressaltam o envolvimento de gestores para elaboração de propostas educativas que contemplem a inserção de recursos educacionais digitais e das TDIC nos currículos.

Sendo assim, uma das abordagens possíveis para se compreender que estratégias as escolas de Educação Básica adotaram para manutenção das atividades letivas durante a quarentena, nos sistemas público e privado, é interagir e dialogar com seus gestores e capturar suas perspectivas. A partir disso, será possível realizar triangulações com o que se conhece sobre a incorporação de TDIC e de outros recursos no contexto da sala de aula, reconstituída, neste momento, em um espaço virtual de interações - síncronas ou assíncronas.

\section{PERCURSO METODOLÓGICO}

A pesquisa adotou abordagem qualitativa e exploratória, desenhada como estudo de caso orientado pela Teoria Fundamentada em Dados de Charmaz (2009). Segundo essa autora, na TFD, os dados formam a base para a elaboração de uma teoria, e a análise que o pesquisador faz desses dados pode dar origem a novos aspectos relevantes em relação ao foco da pesquisa. Essa abordagem tem como premissa que o desenvolvimento de teorias pode se dar a partir da investigação baseada nos dados da realidade investigada, em contraponto ao modelo de dedução de hipóteses analisáveis, geradas previamente, a partir de teorias já existentes. Segundo Charmaz (2009, p. 24) qualquer versão teórica já conhecida oferece um retrato interpretativo do mundo estudado e não um quadro fiel dele, ou seja, "o presente resulta do passado, mas nunca é exatamente a mesma coisa".

De acordo com Fragoso, Recuero e Amaral (2011, p. 110) ao valorizar a experiência empírica e a análise dos dados, essa abordagem é recomendada para estudo de "temáticas novas e com poucas fontes bibliográficas", como é o caso do fenômeno do funcionamento das escolas de Educação Básica durante a pandemia da COVID-19.

A partir desses pressupostos metodológicos, a pesquisa buscou a análise sistemática dos dados gerados a partir de entrevistas semiestruturadas realizadas com gestoras de 2 escolas 
públicas e 2 particulares de um município de aproximadamente 100 mil habitantes no interior de Minas Gerais.

A amostragem (CHARMAZ, 2009), dirigida a construção da teoria fundamentada, foi constituída a partir de 4 escolas de um município do interior de Minas Gerais que conta com 56 escolas de Educação Básica e que tiveram as aulas interrompidas no dia 18 do mês de março de 2020, atingindo cerca de mais de 20 mil estudantes, sendo 5 mil deles estudantes do Ensino Fundamental II - anos finais, segundo dados do Censo 2018. A amostra consistiu de gestoras de escolas municipais públicas e particulares da Educação Básica, que atendem alunos do Ensino Fundamental II - anos finais. Essas profissionais foram entrevistadas para se obter as percepções e o detalhamento das estratégias adotadas na manutenção das atividades letivas durante a quarentena. As entrevistas aconteceram por meio do Google Meet, respeitando-se o isolamento social.

Depois de cada entrevista, os pesquisadores analisaram, discutiram os dados coletados e organizaram nova entrevista para que os novos dados obtidos pudessem contribuir no enriquecimento dos aspectos previamente abordados pela entrevistada anterior. Dessa forma, foram mapeadas as estratégias educacionais adotadas pela gestão das escolas, gerando referências que permitirão analisar as consequências de curto e médio prazo, quando o isolamento social não for mais necessário.

Subsidiariamente, na análise das respostas e para articulação das narrativas, utilizou-se a metodologia do Discurso do Sujeito Coletivo (DSC), desenvolvida por Lefevre e Lefevre (2003; 2006). O DSC constitui-se em uma proposta metodológica que contempla informações comuns a distintos discursos individuais, reconstruindo-as como pensamento coletivo. Ao final do processo, obtém-se a narrativa na forma de depoimento coletivo constituído por trechos de distintos depoimentos individuais.

Assim, a partir da análise dos dados das entrevistas, foram extraídas as ideais centrais das respostas de cada indivíduo e, posteriormente, construídos os DSCs, tendo como objetivo expressar empiricamente o pensamento do grupo de participantes como um coletivo, e não como ser individual, criando assim um ente pensante único, com voz e respostas às perguntas efetuadas.

\section{OBSERVAÇÕES E DISCUSSÕES}

As discussões e análises decorrentes das observações proporcionadas pelas entrevistas e a contemplação do contexto foram elaboradas de acordo com a seguinte trilha baseada na TFD: (a) realização simultânea da análise com a coleta dos dados; (b) codificação e categorização analítica que emergiram dos dados, representadas por item descritivo presente neste tópico; (c) elaboração de comparações entre as realidades das instituições públicas e privadas concomitantemente com o processo de categorização; (d) redação do memorando com descrição analítica do fenômeno - elaborado neste tópico; (e) articulação de um construto teórico que fundamente as análises - apresentado nas Conclusões. 


\subsection{Contexto}

As entrevistas com as gestoras escolares ocorreram durante os meses de novembro e dezembro de 2020. Os dados levantados são referentes às estratégias adotadas para continuação e realização das atividades pedagógicas no período da pandemia, assim como ações de formação continuada e suporte para os professores e estudantes, buscando ampliar a visão das potencialidades e dificuldades sobre o isolamento social, o Ensino Remoto Emergencial, bem como acerca do uso das tecnologias digitais de informação e comunicação disponíveis.

As escolas públicas apresentam média de 622 estudantes matriculados no ano de 2020 no Ensino Fundamental II - anos finais e contam com uma média de 33 professores. As escolas particulares contam com uma média de 309 estudantes e 33 professores atuando nesse mesmo segmento. Observa-se, portanto, que a média de estudantes por professor é 2 vezes menor nas escolas públicas que nas particulares e isso pode se tornar um problema quando se pretende atender os estudantes de forma mais individualizada.

As quatro escolas pesquisadas apresentam padrões socioeconômicos diferenciados da população estudantil, três atendendo públicos de classe média baixa e outra um público maior de classe média alta.

As escolas tiveram as aulas presenciais interrompidas no dia 18 de março de 2020 . Foi necessário encontrar alternativas para a realização das atividades pedagógicas a fim de que professores e estudantes pudessem continuar o processo de ensino aprendizagem mesmo diante do cenário de fechamento das estruturas físicas das unidades escolares. Segundo as gestoras, o desafio foi fazer com que a educação pudesse transpor as barreiras físicas e conseguisse encontrar meios de chegar à casa de todos os envolvidos no processo educacional, seja por meios digitais (TDIC) ou não. Desse modo, foi preciso tomar decisões, rapidamente, sobre como dar continuidade às atividades letivas, de forma remota, atendendo às diversas realidades educacionais, econômicas e sociais de professores e estudantes.

Naquele momento, existia uma grande indecisão sobre qual seria a duração do fechamento das escolas. Todas as gestoras enfatizaram o fato de não haver previsibilidade que pudesse indicar se as aulas voltariam presencialmente em 15 dias, um mês ou por mais quanto tempo elas seguiriam completamente fechadas. No caso das instituições particulares, a decisão gerencial por retomar as atividades letivas de forma alternativa foi rápida e se baseou na primazia da continuidade da prestação de serviços. Passados 7 dias da decretação da quarentena, as escolas já haviam decidido quando e como retomariam as atividades. Nas escolas públicas, o processo foi mais demorado, principalmente devido à complexidade do contexto social, aos diferentes níveis de vulnerabilidade dos estudantes, bem como ao total de estudantes e professores envolvidos. A decisão de retorno se deu em setembro de 2020, depois de longo processo de discussões, planejamento e preparação.

\subsection{O Planejamento de ações/estratégias}

As escolas da rede pública municipal tiveram as aulas suspensas durante seis meses, retornando, de forma remota, em $1^{\circ}$ de outubro, com previsão de encerramento do calendário 
letivo no final de janeiro de 2021. Durante esse período, a Secretaria de Educação criou estratégias que pudessem atender a todas as unidades educacionais da rede, num total de 18 escolas, das quais 11 atuam com o segmento do Ensino Fundamental II, com aproximadamente dois mil estudantes.

Segundo as gestoras, a estratégia adotada para atender a todos os alunos da rede pública foi a utilização de Roteiros de Estudo Orientado (REO) como material pedagógico referencial. 0 REO é um documento que tem como objetivo apresentar as informações necessárias para o desenvolvimento de um componente curricular ao longo de um determinado período de trabalho pedagógico - uma semana ou duas semanas -, de forma a orientar a comunicação entre o docente da disciplina e o estudante.

Os REOs foram produzidos pelos professores da rede, depois de terem analisado e revisado o Planejamento Anual de 2020 da Secretaria de Educação do município pesquisado. Para elaborar esses roteiros, os professores criaram grupos em aplicativo de mensagem, organizados por componente curricular de acordo com as normativas estabelecidas pela Base Nacional Curricular Comum (BNCC), e por meio dessa ferramenta compartilhavam materiais e agendavam reuniões pelo Google Meet para elaboração das atividades a serem desenvolvidas. Com essa estratégia, além dos REO, também produziram e reuniram outros materiais pedagógicos que depois seriam postados no Google Classroom ou seriam disponibilizados de forma impressa, quinzenalmente, para serem retirados nas escolas onde os estudantes estavam matriculados.

O REO, disponibilizado na forma impressa para ser retirado na escola pelos familiares ou responsáveis pelos estudantes, foi pensado como forma de atender aqueles que não possuíam dispositivos eletrônicos ou acesso à internet. Os REOs seguiram um modelo padrão de perguntas orientando uma trilha de aprendizagem do aluno, levando em consideração que o professor e a família atuariam como suporte, exercendo um papel fundamental para o apoio e estímulo da aprendizagem, uma vez que os lares acabaram se transformando no novo ambiente escolar.

As famílias podiam optar, dentro das suas condições, por utilizar o ambiente virtual disponibilizado pelas escolas, o Google Classroom, ou buscar o material impresso nas escolas. Além do REO, no formato impresso ou on-line, todos os estudantes da rede pública haviam recebido, no início do ano letivo de 2020, os livros didáticos disponibilizados pelo Programa Nacional do Livro Didático do Ministério da Educação (PNLD); isso foi levado em conta e todas as orientações remeteram a conteúdos trabalhados nos livros.

Em contraponto, as duas escolas particulares, que já tinham o apoio da infraestrutura tecnológica digital existente e de fácil acesso, conseguiram, rapidamente, implementar o uso de ambientes virtuais de aprendizagem (AVA) para dar continuidade ao processo educacional de forma remota. Para conhecer a plataforma adotada e ter acesso ao login e senha, os professores começaram, no mesmo dia da decretação da quarentena pelo governo municipal - suspensão das aulas presenciais -, a participar de cursos de formação em parceria com as equipes de apoio pedagógico das suas instituições. Com base no treinamento acelerado e na preexistência de materiais desenvolvidos, as aulas dessas instituições foram retomadas de forma on-line no dia 23 de março, segunda-feira seguinte ao fechamento das unidades escolares.

Nas escolas particulares, a estratégia adotada foi a retomada das aulas de forma síncrona, por meio de webconferência, obedecendo ao horário de aula que já acontecia no Ensino 
Presencial, com horários fixos e início às 7 horas e término às 12 horas. Essas aulas eram gravadas e os alunos podiam acessá-las também em momento posterior. Em uma das instituições, a gestora explicou que, com a cooperação da equipe pedagógica, o colégio fez um levantamento e conseguiu obter um resultado de $100 \%$ dos alunos com acesso à internet, à plataforma è̀ aulas on-line. Na outra instituição particular pesquisada, que oferece o sistema de internato, foi realizada Busca Ativai para identificar os estudantes que precisavam de algum tipo de apoio, seja por não terem acesso à TDIC, ou por terem dificuldade de utilização dessas tecnologias. Esses alunos foram chamados de volta para o sistema de internato a fim de se integrarem aos estudos e terem um apoio mais próximo da equipe pedagógica, sempre seguindo os protocolos de segurança para prevenção da COVID-19.

As escolas particulares já trabalhavam, rotineiramente, com material impresso, apostilas e livros pedagógicos, e esse material continuou sendo o suporte para os estudantes nas suas casas ou no internato. Não houve uma adaptação de material impresso exclusivamente para esse momento da pandemia. Tudo foi disponibilizado também $100 \%$ de forma on-line, desde os conteúdos pedagógicos, até agendamentos e orientações de trabalhos e atividade avaliativa. Também as reuniões pedagógicas, reuniões com as famílias e o atendimento individualizado foram mediados por TDIC. Basicamente, segundo narrativa das gestoras, todas as atividades que aconteciam de forma presencial foram "transformadas" e adaptadas para acontecerem por meio de web conferências ou suportadas pelos recursos das plataformas digitais (AVA).

É relevante destacar que, embora as duas escolas estivessem dentro de centros universitários com infraestrutura para AVA, não havia nenhum projeto ou planejamento para o uso dessas ferramentas na Educação Básica. As entrevistadas asseguram que foi o isolamento social causado pela pandemia da COVID-19 que trouxe, efetivamente, a necessidade do uso dos recursos educacionais digitais nas práticas pedagógicas da instituição e que, muito possivelmente, se isso não tivesse acontecido, a escola ainda trabalharia da mesma forma, convencional, com material impresso e aulas presenciais.

As gestoras das instituições particulares enfatizam que, embora o processo de implantação do ambiente virtual tenha sido facilitado pela infraestrutura preexistente dos sistemas educacionais dos quais fazem parte, é impossível não descrever e ponderar que o processo de apropriação dessas ferramentas para uso pedagógico por professores e estudantes não foi fácil.

Observou-se que tanto nas escolas públicas como nas particulares muitos dos desafios e dificuldades só foram desvelados no momento da implementação do Ensino Remoto Emergencial: professores que não tinham domínio dos recursos tecnológicos - mesmo os mais básicos - apesar de não declararem; dificuldade de apoio pedagógico por parte pais e responsáveis - que não têm a habilidade para ensinar; limitação financeira de famílias e de professores que, inclusive, foi exacerbada neste momento de crise; dentre outros.

\subsection{A escolha dos recursos para apoio ao ensino}

A escolha dos recursos tecnológicos que seriam adotados para dar continuidade às atividades letivas foi ponto determinante para que os planos de ação e estratégias pudessem ser colocados em prática. 
As escolas da rede municipal buscaram parcerias com o Google para a utilização do domínio educacional, para criação dos e-mails institucionais e utilização das ferramentas G-suit for education de forma gratuita. Por meio dessa parceria, todos os gestores, professores e estudantes receberam um e-mail institucional, com login e senha, para acesso a diversas ferramentas on-line que poderiam ser utilizadas para facilitar a comunicação e o aprendizado. A Secretaria de Educação do município disponibilizou dois sites, um para professores e outro para os estudantes e familiares, com diversos tutoriais, vídeos com passo a passo, telefone de contato, além de e-mail para suporte. Esses sites, segundo as gestoras, foram de grande importância e facilitadores para que a maioria conseguisse acessar o e-mail institucional e, principalmente, o Google Classroom, a plataforma virtual eleita para dar sustentação ao ERE.

As duas escolas particulares têm em comum o fato de serem parte integrante de um ambiente educativo mais amplo, pois estão estruturadas dentro de sistemas educacionais que atendem estudantes desde a Educação Infantil até o Ensino Superior e que oferecem também cursos de graduação à distância. Um ponto em comum dessas instituições escolares é o fato de estarem integradas - fisicamente, inclusive - a centros universitários que já possuíam e utilizavam, para os cursos de graduação, plataformas virtuais e aplicativos de gerenciamento educacional. Segundo as gestoras, esse foi um facilitador, pois as duas escolas puderam contar com infraestrutura pronta, que foi apenas estendida para atender à Educação Básica. Nesse aspecto, os relatos dos gestores estão de acordo com a literatura quando esta aponta que as estruturas e recursos TDIC existentes e disponíveis nas instituições educacionais favorecerem a incorporação de atividades letivas mediadas por TDIC ao currículo.

Nas instituições públicas, foi necessário buscar parceria para se ter acesso aos recursos das TDIC e isso retardou a retomada das atividades letivas. Outro diferencial observado foi o fato de, nas escolas particulares, os departamentos de tecnologia da informação colaboraram oferecendo suporte remoto e apoio para as famílias e aos professores que estavam trabalhando e estudando em casa com seus próprios equipamentos. As escolas particulares adotaram plataformas proprietárias: Blackboard Learn, Zoom e Microsoft Teams.

\subsection{Preparação dos professores}

As gestoras das escolas públicas relatam que, no mês de junho de 2020, a Secretaria Municipal de Educação, por meio de uma parceria com uma universidade pública federal, ofereceu aos professores da rede cursos de formação e aprimoramento para o uso de tecnologias necessárias à efetivação do ERE. Nessa parceria com a universidade, foram realizadas, durante três semanas, palestras, cursos e oficinas práticas, de forma que os professores pudessem conhecer e aprender a utilizar, efetivamente, as TDIC na prática pedagógica.

Segundo as gestoras, a maioria dos professores demonstrou interesse em participar dos cursos de formação. Segundo a Secretaria de Educação do município pesquisado, a média diária de participantes foi próxima de 400 pessoas on-line. As atividades permitiram interação por postagens em chat e também por meio dos recursos do Google Classroom. Ao final de cada formação, os participantes respondiam a um questionário on-line, que foi utilizado para diagnosticar o uso de tecnologias pelos professores da rede municipal. 
Todas as atividades realizadas durante as três semanas foram gravadas e disponibilizadas em um canal no Youtube para que os professores que não pudessem participar de forma síncrona tivessem a oportunidade de assistir depois, sem ficarem prejudicados. Os vídeos disponibilizados no canal contam com mais de 3 mil visualizações, tendo dessa forma, alcançado outros professores além dos profissionais da própria rede municipal.

Nas unidades particulares, os professores começaram as formações no momento da decretação da quarentena - março de 2020. Inicialmente, houve ação intensiva de cursos oferecidos, em dias e horários diferentes, para atendimento a todos os professores. Segundo as gestoras, em seguida, foram acontecendo formações mais espaçadas, mas sempre buscando transformar a prática da aula presencial para atividades on-line, com metodologia diferenciada. As gestoras ressaltaram que a participação dos professores e da equipe pedagógica aconteceu de forma intensa. Entende-se que tal fato se justifica pela própria natureza da relação trabalhista existente nesses ambientes educacionais. As escolas criaram comissões para discussão do Ensino Remoto e grupos de estudo para captação das melhores práticas, com professores trocando experiências e ajudando uns aos outros.

Foi possível observar, nas narrativas das gestoras e na análise do contexto, que os cursos de formação dos professores ocuparam a centralidade das estratégias para retomada das atividades letivas, tanto nas instituições públicas quanto nas particulares. Esses cursos constituíram-se em elemento fundamental para o relativo sucesso das iniciativas de ERE. Observamos, também, que foi necessário o estabelecimento de novos vínculos com esses profissionais, pois sem efetiva adesão e dedicação não se organizaria, tão rapidamente, uma retomada, mesmo que em alguns aspectos precária, das atividades letivas. Os professores foram induzidos pelas circunstâncias a repensarem suas práticas e a, com criatividade, pensarem seus próprios processos de aprendizagem enquanto planejavam novas formas de lecionar.

\subsection{Participação dos pais/responsáveis e estudantes}

As gestoras relatam efetiva participação e envolvimento da maioria dos pais e da comunidade escolar no desenvolvimento das atividades que foram adotadas para a realização do ERE. No âmbito da educação pública, houve mobilização e cobrança por parte da sociedade local para que atividades letivas pudessem ser retomadas e o ano de 2020 não fosse anulado.

Para as escolas públicas municipais, a divulgação da implantação do ERE para as comunidades escolares - incluindo familiares - foi realizada por meio das redes sociais da Prefeitura Municipal e também por meio de grupos de aplicativo de mensagens que foram criados por escola. As gestoras mencionam que a implementação do Ensino Remoto foi bem acolhida pelos estudantes e pela comunidade escolar, pois já havia ansiedade pela retomada das atividades escolares. Afinal, foram cerca de 6 meses sem aulas.

As gestoras das escolas públicas destacaram que, inicialmente, uma das maiores dificuldades era o reduzido número de acessos aos ambientes virtuais, porque parte dos alunos não tinham equipamentos adequados ou não tinham acesso à internet. Elas descrevem que alguns familiares se organizaram para reprogramar seus próprios orçamentos a fim de poderem comprar equipamentos e melhorar o pacote de dados de acesso à internet. Houve também um 
grupo que residia em locais onde o sinal telefônico para acesso à internet era de baixa qualidade, intermitente ou inexistente.

No início da adoção do Ensino Remoto Emergencial na rede pública municipal, uma grande parcela de pais e responsáveis optou pela retirada do material impresso na escola. Mesmo as famílias que contavam com equipamentos e conexão de internet viável para as atividades on-line preferiram os materiais impressos. Segundo as gestoras entrevistadas, isso se deu por desconfiança ou desconhecimento de como utilizariam os recursos tecnológicos e como as crianças e jovens conseguiriam estudar mediadas por TDIC. Houve inúmeras manifestações de falta de credibilidade do estudo on-line. Alguns pais comentaram, segundo as gestoras, que os jovens e estudantes já ficavam grande parte do dia conectados pelo celular e que era preciso que eles "sentassem e abrissem os livros para estudar". Mesmo com muitos diálogos e informações divulgadas pela equipe pedagógica para as famílias, a maioria dos pais ou responsáveis teve receio dos resultados do estudo por meio digital e optou pelo material impresso.

As gestoras ressaltaram que, no decorrer do processo, o número de alunos que retirou o material na escola e iniciou, simultaneamente, o acesso ao ambiente virtual, ampliou-se a cada semana. Elas apontaram um fenômeno relevante que ocorreu nesse processo: à medida que os alunos começavam a acessar cada vez mais o ambiente virtual de aprendizagem e a realizar as atividades dos REO no Google Classroom, elas imaginaram que os estudantes e as famílias abririam mão do material impresso; entretanto, isso não ocorreu. Embora os estudantes estivessem a cada dia mais ativos nos ambientes virtuais, a maioria continuou com a rotina de se deslocar até a escola para retirar o material impresso, fazendo assim o uso dos dois recursos para estudar.

Pelas informações obtidas, foi minoria as famílias e estudantes que não retiraram o material impresso e também não acessaram as ferramentas digitais para continuarem os estudos. A estratégia das escolas foi realizar Busca Ativa. Aqueles que não foram localizados tiveram seus casos encaminhados para o Conselho Tutelar ou para o Ministério Público.

Nas unidades particulares, as gestoras relataram que a presença dos pais e as cobranças por parte das famílias são mais acentuadas. Elas ressaltam que, nesse contexto de pandemia da COVID-19, a participação familiar foi muito produtiva e proativa. Segundo os relatos, a dificuldade mais evidenciada nas interações com os pais foi a adaptação de crianças dos anos iniciais do fundamental, que ainda necessitam de mais apoio e acompanhamento.

Para os estudantes do Ensino Fundamental II a adaptação foi mais simples e prática. As dificuldades identificadas foram mapeadas rapidamente gerando adaptações necessárias para que o ensino e a aprendizagem pudessem continuar acontecendo de forma on-line. As formações para acesso às plataformas digitais ocorreram por meio de lives, reuniões on-line, e, se necessário, contatos telefônicos com os estudantes e suas famílias. Por meio desse contato próximo e persistente, o processo de estudo remoto foi ensinado passo a passo desde o acesso aos ambientes em que seriam disponibilizados as atividades on-line até a realização das atividades, leitura de textos, estudo por meio de vídeos e acesso às aulas síncronas, por intermédio dos aplicativos Zoom e Microsoft Teams.

As unidades educacionais particulares também adotaram o uso de aplicativos gerenciais que monitoram, por meio de gráficos e mapeamento em tempo real, os dados de desempenho e 
participação dos estudantes e professores. Tais recursos permitiram o acompanhamento e a supervisão, bem como auxiliaram no processo de busca por estudantes que deixavam de participar das atividades.

Observou-se, também nessa categoria, diferença significativa de estratégias entre instituições públicas e particulares, advindas principalmente das características socioeconômicas dos estudantes e famílias, dos recursos tecnológicos disponíveis e dos diferentes modelos de gestão. Apesar das diferenças, nota-se que houve adesão e comprometimento da maioria das famílias para que se viabilizasse a continuidade dos estudos durante a quarentena.

\subsection{Resultados Iniciais}

Na visão das gestoras da rede pública entrevistadas, as estratégias adotadas para retomada das atividades letivas se demonstraram eficientes, principalmente, porque se deslocaram da pretensa necessidade de recursos tecnológicos sofisticados para a busca por alternativas de apoio e orientação aos estudantes, sejam mediadas por tecnologias digitais, ou por meio do bom e velho material impresso. Observa-se que se centraram em disponibilizar aos estudantes o material pedagógico e as orientações necessárias para os estudos, ambos elaborados e preparados pelos próprios professores, dentro da realidade educacional do qual estão inseridos.

Outro grande ganho apontado pelas gestoras foi o trabalho em rede, realizado por meio de diversas reuniões e encontros virtuais, por cursos de formação para novas estratégias didáticas, pela reestruturação e reelaboração do Planejamento Anual da Educação Municipal, que permitiram a reformulação do material didático que chegaria às mãos dos estudantes. AS entrevistadas destacam o trabalho em equipe realizado de forma colaborativa: "um ajudando o outro à medida que apareciam as dificuldades", nas palavras de uma das gestoras, como uma consequência benéfica do enfrentamento da pandemia no campo educacional.

É predominante na fala das gestoras que muitas atividades que aconteceram e se transformaram durante a realização do ERE permanecerão no período pós-pandemia. Elas citaram, como exemplo, as reuniões on-line com professores, reuniões on-line com pais, o uso das ferramentas G-Suite for Education e do Google Classroom como parte da possibilidade de um ensino semipresencial, além das estratégias e organização dos estudos por meio dos Roteiros de Estudo Orientados.

Para as gestoras da rede pública municipal, a implementação do Ensino Remoto Emergencial foi um grande desafio, mas o resultado é positivo, por gerar muitas possibilidades de aprendizado e crescimento, por permitir que todos aprendessem o teletrabalho colaborativo e em rede, tendo como premissa a realidade na qual estão inseridos os professores e estudantes.

Nas instituições particulares, percebeu-se, pelas manifestações das gestoras, que manterão em suas estratégias educacionais a utilização dos recursos digitais que foram incorporados devido à pandemia. Foram apontados como heranças desta experiência com as atividades letivas remotas: o uso de ambientes virtuais de aprendizagem; aulas síncronas e plantões pedagógicos on-line; as reuniões pedagógicas e conselhos de classe on-line; os cursos 
de formação; as trocas de boas práticas; o atendimento individualizado às famílias, todos mediados por tecnologias.

As gestoras das escolas particulares mencionam que, mesmo com as dificuldades, esse processo foi muito importante para um aprendizado de todos os profissionais da educação, principalmente professores e estudantes que se esforçaram e se dedicaram a fazer o ensino acontecer de forma remota. 0 papel dos professores, a dedicação e o profissionalismo, mais uma vez, foram os destaques positivos para a realização das atividades letivas, também no formato remoto. Foram os professores que buscaram estratégias de inovação para aulas "diferentes", bem como entender o cenário e pensar em metodologias que fossem significativas para o formato on-line. Foram eles os protagonistas para que a educação pudesse acontecer por meio do Ensino Remoto Emergencial, levando o processo de aprendizado para fora dos espaços físicos já conhecidos.

\section{CONCLUSÕES: TEORIZAÇÃO INICIAL}

Tendo como base os pressupostos da TFD (CHARMAZ, 2009), a pesquisa, cuja etapa inicial é apresentada neste artigo, buscará, em sua conclusão, articular um construto teórico que fundamente análises acerca das estratégias utilizadas na Educação Básica para a superação da quarentena imposta pela pandemia nos anos de 2020 e 2021, bem como seus efeitos. Os dados obtidos, até o momento, por meio de diálogo com gestores e da observação participante do fenômeno ainda em curso, bem como sua sistematização analítica permitem elaborar teorizações iniciais que são apresentadas como conclusão deste relato. Trata-se, portanto, da primeira aproximação sistêmica com o fenômeno, geradora de hipóteses que nortearão a obtenção de novos dados e de novas análises.

No processo de análise e construção das categorizações registradas nas observações e discussões - memorando -, ficou evidente que o contexto gerado pela COVID-19 atingiu, de forma igual, as escolas dos dois sistemas - público e particular. Apesar disso, o conjunto de fatores indutores da retomada das atividades letivas no formato de estudo remoto experimentou forças de impulso distintas, provocando retorno praticamente imediato nas escolas particulares, enquanto que, na rede municipal, houve um longo processo de decisões e de preparação.

Em ambas se observou distanciamento dos pressupostos teórico-conceituais que caracterizam a Educação a Distância, reforçando argumentos dos que defendem a não aplicabilidade de tais pressupostos às atividades letivas remotas dos cursos presenciais desenvolvidas no contexto da pandemia (MARTINS, 2020; ARRUDA, 2020).

Os relatos das gestoras dão pistas sobre tais fatores e as forças que operaram sobre eles. A hipótese é que a lógica da prestação de serviços - predominante nas instituições particulares -; a fonte do custeio das escolas; o tipo de relação trabalhista com os docentes; as características socioeconômicas dos estudantes e suas famílias; o acesso e o domínio dos recursos tecnológicos adequados; e a disponibilidade de apoio técnico-operacional sejam os fatores preponderantes que levaram à diferenciação significativa no tempo e no formato adotado para as atividades letivas remotas. Tais hipóteses precisam ser investigadas com observações em campo, por meio de escuta cuidadosa de docentes, estudantes e seus familiares. Depois, precisam ser 
confrontadas com a literatura que evidencia diferenças entre o ensino público e privado no Brasil para se identificar se tais fatores foram exacerbados pela pandemia.

Especificamente quanto ao acesso e disponibilidade de recursos tecnológicos, evidenciouse que, nas escolas particulares investigadas, a disponibilidade de estruturas e recursos educacionais digitais preexistentes, a princípio, parecem coadunar com o que Kenski (2003) e Moran (2007) apontam: a existência de espaços de estudos em ambientes virtuais com novas concepções que vão além de projetos de educação a distância favorecem novas concepções de educação. Entretanto, ao se analisar criticamente o processo de transposição das atividades letivas presenciais para os ambientes virtuais adotados nas escolas particulares pesquisadas, observou-se que não houve tempo hábil para incorporação de conceitos relacionados ao desenho de cursos mediados por tecnologia tais como o design educacional contextualizado, por exemplo.

Segundo (FILATRO, 2019), o design contextualizado é uma metodologia de planejamento que consiste em identificar problema de aprendizagem e criar, implementar e analisar uma solução para esse problema. Esse método evoca a investigação profunda do contexto e da cultura do público-alvo, bem como a identificação das necessidades específicas dos professores, estudantes e da instituição para, então, iniciar-se o planejamento de soluções de ensinoaprendizagem.

Outro aspecto teórico-conceitual não observado foi o que dá suporte à mediação pedagógica gerada pela incorporação das TDIC ao currículo (MORAN; MASETTO; BEHRENS, 2013). Esses aportes teóricos são conhecidos há, pelo menos, duas décadas.

Os relatos e a observação do contexto de implantação das atividades de Ensino Remoto nas escolas particulares evidenciam que houve, a princípio, uma transposição linear do que ocorria nas aulas presenciais para sessões de webconferência, com material adicional para atividades em casa. Há evidências, portanto, a serem confirmadas com a coleta de novos dados de que os recursos tecnológicos foram utilizados na perspectiva da Incorporação Instrumental discutida por Peixoto e Araújo (2012, p. 256).

Em contraponto, na rede pública, apesar da condição de urgência na retomada das atividades letivas, entre a identificação da necessidade de se adotarem estratégias para atividades letivas a distância e a implantação das primeiras ações houve um tempo considerável - seis meses. Nesse tempo, elaborou-se um desenho educacional contextualizado às demandas da comunidade educacional - foram pensados materiais e mídias que permitissem que diferentes perfis de estudantes e famílias participassem das atividades letivas -; buscou-se parceria para obtenção de recursos tecnológicos necessários às interações síncronas e assíncronas, bem como preparar os docentes e estudantes para a nova forma de ensino-aprendizagem que seria adotada. Considera-se que, no projeto da rede pública, não predominou a visão instrumental de incorporação das TDIC. Tal projeto, porém, também não ficou livre do determinismo tecnológico, termo adotado aqui assim como descrito por Peixoto e Araújo (2012, p. 256).

Se, por um lado, a estratégia adotada pela rede pública permitiu melhor sustentação teórico-conceitual e condições mais adequadas, do ponto de vista da educação mediada por TDIC, por outro gerou desmobilização temporária de estudantes e descontinuidade de estudos por seis meses. Questiona-se, então, qual das estratégias adotadas foi a mais efetiva - ou gerou 
menos danos - para o atendimento às demandas educacionais geradas pela prolongada quarentena?

A visão de que as TDIC são um benefício educacional capaz de melhorar o ensino e a aprendizagem apareceu como pano de fundo nos resultados narrados pelas gestoras entrevistadas. Essa visão está presente, com muita frequência, nos textos que contemplam um paradigma educacional de inserção de tecnologias denominado Obstrucionista. Segundo Pappert (2008), autor do termo, tal paradigma expressa algo diferente do instrucionismo Skinneriano. Para o referido autor, trata-se de um nível pragmático, arraigado na crença de que o aperfeiçoamento do ensino, per si, é fator de melhoria da aprendizagem. Ainda o mesmo autor propôs um contraponto: a abordagem construcionista. Pappert evoca esse termo a partir do construtivismo Piagetiano. Essa base conceitual, que encontra suporte e coerência nas teorias psicológicas da aprendizagem, requer, para efetiva aplicação, preparo dos docentes, tanto nos pressupostos educacionais quanto na aplicação coerente dos recursos tecnológicos digitais como instrumentos mediadores do ensino-aprendizagem.

Segundo Cardoso, Azevedo e Martins (2013), ao se analisar a produção sobre tecnologia educacional, observa-se que o referencial bibliográfico predominante apresenta as TDIC como recursos didático-pedagógicos centrados no paradigma construtivista, afirmação que está de acordo com as análises de Peixoto e Araújo (2012). Nessa abordagem, o papel da tecnologia nos processos de ensino está subordinado à competência do professor como mediador e facilitador do processo de aprendizagem do aluno, que é descrito como um sujeito autônomo, construtor de conhecimentos. Apesar disso, a pretensa sustentação na teoria interacionista da incorporação de TDIC aos processos de aprendizagem, via de regra, não se articula profundamente com o conjunto de atividades educacionais propostas ou desenvolvidas a partir da mediação das TDIC (PEIXOTO; ARAÚJO, 2012). Isso se dá por déficits de formação específica do corpo docente, equívocos nos planos e projetos de incorporação dos recursos educacionais digitais ao currículo e vieses na gestão educacional, nos diversos níveis do sistema (MARTINS; PAIVA, 2017; ALMEIDA; VALENTE, 2011).

A centralidade do processo de formação de professores para a viabilidade da adoção do Ensino Remoto merece, portanto, um olhar analítico e crítico quanto à sua teorização. Segundo Shulman (1987), tal preparo envolve conhecimentos de conteúdos e conhecimentos pedagógicos do ensino-aprendizagem desses conteúdos, ou seja, incorporar tecnologias digitais educacionais requer conhecimento pedagógico específico acerca de sua integração com o ensino dos conceitos e processos. Isso transcende o domínio competente e instrumental dos artefatos e recursos tecnológicos. Não basta saber operar bem os artefatos e ser hábil com os recursos, é preciso saber ensinar e aprender, aplicando-os de forma competente.

Moran (2007) destaca a necessidade de formação adequada para os docentes, mas aponta que as transformações relacionadas ao uso das TDIC afetam igualmente tudo e todos. O professor não pode, sozinho, resolver as complexas questões que envolvem o papel da escola frente a adoção de TDIC nas práticas pedagógicas. Dos relatos obtidos, destaca-se, também, a necessidade de investigação aprofundada, por meio da escuta cuidadosa dos professores, sobre como foram distribuídas as responsabilidades e os trabalhos para que se pudesse realizar as 
atividades letivas a distância e quais foram os desdobramentos profissionais e pessoais dessa carga laboral para esses profissionais.

\section{REFERÊNCIAS}

ALMEIDA, M. E. B.; VALENTE, J. A. Tecnologias e currículo: trajetórias convergentes ou divergentes. São Paulo: Paulus, 2011.

ARRUDA, E. P. Implementação das tecnologias digitais nos currículos das escolas de Educação Básica dos países membros da OCDE. In: SIQUEIRA, I. C. P. (Org.). Subsídios à elaboração da BNCC: estudos sobre temas estratégicos da parceria CNE e Unesco. São Paulo: Moderna, 2018.

ARRUDA, E. P.. Educação Remota Emergencial: elementos para políticas públicas na educação brasileira em tempos de Covid-19. EmRede: Revista de Educação a Distância, Porto Alegre, v. 7, n. 1, p. 257-275, 2020. Disponível em: Acesso em: 26 fev. 2021.

BEHAR, P. A. O ensino remoto emergencial e a educação à distância. 2020. Disponível em:

https://www.ufrgs.br/coronavirus/base/artigo-o-ensino-remoto-emergencial-e-a-educacao-a-distancia/. Acesso em: 06 jun. 2020.

CARDOSO, A. M.; AZEVEDO, J. F.; MARTINS, R. X. Histórico e tendências de aplicação das tecnologias no sistema educacional brasileiro. Colabor@: Revista Digital da CVA, Porto Alegre, v. 8, n. 30, dez. 2013. Disponível em: http://repositorio.ufla.br/handle/1/11448. Acesso em: 26 fev. 2021.

CARVALHO, M. D.; MARTINS, R. X. Coordenação pedagógicas na Era Digital: Perspectivas de atuação na Educação Básica. Saarbrücken, Alemanha: Novas Edições Acadêmicas, 2017.

CHARMAZ, K. A construção da teoria fundamentada: guia prático para análise qualitativa. Porto Alegre: Artmed, 2009.

FILATRO, A. Design instrucional contextualizado: educação e tecnologia. São Paulo: Senac São Paulo, 2019.

FRAGOSO, S.; RECUERO, R.; AMARAL, A. Métodos de pesquisa para internet. Porto Alegre: Sulina, 2011.

KENSKI, V. M. Educação e tecnologias: o novo ritmo da informação. Campinas: Papirus, 2003.

LEFEVRE, F.; LEFEVRE, A. M. C. 0 discurso do sujeito coletivo: um novo enfoque em pesquisa qualitativa. Caxias do Sul: EDUCS, 2003.

LEFEVRE, F.; LEFEVRE, A. M. C. O sujeito coletivo que fala. Interface, Botucatu, v. 10, n. 20, p. 517-524, 2006. Disponível em: https://www.scielo.br/j/icse/a/QQw8VZh7pYTwz9dGyKvpx4h/?lang=pt. Acesso em: 26 fev. 2021.

MARTINS, R. X. A COVID-19 e o Fim da Educação a Distância: um ensaio. EmRede: Revista de Educação a Distância, Porto Alegre, v. 7, n. 1, p. 242-256, 2020. Disponível em:

https://www.aunirede.org.br/revista/index.php/emrede/article/view/620. Acesso em: 26 fev. 2021.

MARTINS, R. X.; PAIVA, V. F. F. Era uma vez o Proinfo... diferenças entre metas e resultados em escolas públicas municipais. Horizontes, Itatiba, v. 35, n. 2, p. 17-26, ago. 2017. Disponível em:

https://revistahorizontes.usf.edu.br/horizontes/article/view/319. Acesso em: 26 fev. 2021. 
MORAN, J. M. Ensino e Aprendizagem Inovadores com Apoio das Tecnologias. In: MORAN, J. M.; MASETTO, M. T.; BEHRENS, M. A. Novas tecnologias e mediação pedagógica. 2. Ed. Campinas: Papirus, 2013.

MORAN, J. M. A educação que desejamos: novos desafios e como chegar lá. Campinas: Papirus, 2007.

MORAN, J. M.; MASETTO, M. T.; BEHRENS, M. A. Novas tecnologias e mediação pedagógica. Campinas: Papirus, 2013.

PAPERT, S. A máquina das crianças: repensando a escola na era da informática. Porto Alegre: Artmed. 2008.

PASINATO, N. M. B.; VOSGERAU, D. S. R. Proposta para avaliação dos estágios de integração das TIC na escola. In: Congresso Nacional de Educação, 10., 2011. Anais [...]. Curitiba: PUCPR, 2011. Disponível em: https://educere.bruc.com.br/CD2011/pdf/6451_3806.pdf. Acesso em: 26 fev. 2021.

PEIXOTO, J.; ARAÚJO, C. H. S. Tecnologia e educação: algumas considerações sobre o discurso pedagógico contemporâneo. Educação \& Sociedade, Campinas, v. 33, n. 118, p. 253-268, 2012. Disponível em: https://www.scielo.br/j/es/a/fKjYHb7qD8nK4MWQZFchr6K/?format=pdf\&lang=pt. Acesso em: 26 fev. 2021.

REIMERS, F. M.; SCHLEICHER, A. A framework to guide an education response to the COVID-19 Pandemic of 2020. France: OECD, 2020. Disponível em: https://www.aforges.org/wpcontent/uploads/2020/04/framework.pdf. Acesso em: 26 fev. 2021.

RIBEIRO, A. E. Education and digital technologies in the pandemic: cicles of precariousness. Cadernos de Linguística, v. 2, n. 1, p. 01-16, Jan. 2021. Disponível em:

https://cadernos.abralin.org/index.php/cadernos/article/view/270. Acesso em: 26 fev. 2021.

SHULMAN, L. Knowledge and teaching: foundations of the new reform. Harvard Education Review, Cambridge, v. 57, n. 1, p. 1-22, 1987. Disponível em: https://meridian.allenpress.com/her/articleabstract/57/1/1/31319/Knowledge-and-Teaching-Foundations-of-the-New?redirectedFrom=fulltext. Acesso em: 26 fev. 2021.

SILVA, G. G. R. Diagnóstico da inserção de tecnologias educacionais em escolas de ensino fundamental do interior de Minas Gerais. 2019. Dissertação (Mestrado Profissional em Educação)Universidade Federal de Lavras, Lavras, 2019. Disponível em:

http://repositorio.ufla.br/jspui/handle/1/34468. Acesso em: 26 fev. 2021.

ORGANIZAÇÃO DAS NAÇÕES UNIDAS PARA A EDUCAÇÃO, A CIÊNCIA E A CULTURA (UNESCO). Coalizão Global de Educação. 2020. Disponível em:

https://pt.unesco.org/covid19/educationresponse/globalcoalition\#. Acesso em: 25 jan. 2020.

\footnotetext{
' Busca Ativa é uma estratégia do Plano Brasil Sem Miséria que significa levar o Estado ao cidadão. No contexto, utilizou-se esse conceito para estruturação de ações que permitissem a identificação de estudantes com necessidade de apoio aos estudos, mesmo que tais discentes não buscassem suporte nas escolas.
} 